\title{
Los Indignados: testigos de una transformación social
}

\author{
Poverty measurements in crisis contexts. \\ A view from social citizenship
}

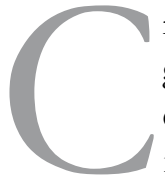

reer que habitamos en un tiempo de grandes libertades en el que se han dejado atrás las restricciones a las que fueron sometidos los hombres y las mujeres de otras épocas, suele pagarse a un precio muy alto: implica renunciar al poder trasformador de la palabra. En últimas, esto también replantea la pregunta por la condición de los sujetos, ahora escindidos y atravesados por múltiples enunciados subjetivos que los desgarran.

En las sociedades postmodernas se han reducido las barreras morales, culturales, políticas y jurídicas que en otras épocas regulaban el acceso del sujeto a aquellos objetos y experiencias que le procuraban satisfacción, así mismo se han reducido las modalidades de encuentro entre los sujetos y las formas de significar las experiencias. El mundo se ha empobrecido a causa de la expansión totalizante del neoliberalismo que pretende convertirlo todo en mercancía, incluso al mismo ser humano, de tal modo que se puede soñar en las libertades abstractas, lo que no está permitido es anhelar siquiera, a colocarse por fuera del consumo, pues el mercado se transformó en la institución que constituye la pertenencia a la sociedad, e incluso, en el brumoso concepto de ciudadanía.

Hasta hace unas décadas, la vida humana se había caracterizado por transcurrir en medio de un conjunto de economías diversas que se expresaban en los encuentros cotidianos de los sujetos, estos intercambios se identificaban por estar plenamente cargados de valores simbólicos que permitían renovar los vínculos solidarios y comunitarios, ya que su objetivo no era la consecución de una satisfacción o ganancia inmediata. Ejemplo de estas economías son aquellos intercambios realizados bajo la lógica del "don", que son una forma de tejer relaciones dando al otro algo que nos cuesta, lo que nos implica un esfuerzo o, como en el caso del enamorado, entregando al ser amado aquello que le hace falta, entregando lo que no se tiene a través de palabras

1 Johnny Albert Vélez es psicólogo y magister en Psicoanálisis, subjetividad y cultura de la Universidad Nacional de Colombia. Coordinador de proyectos de investigación del Centro de Estudios e Investigaciones Humanas y Sociales - CEIHS de la Corporación Universitaria Minuto de Dios.

2 Oscar Useche Aldana es el Director de la Revista Polisemia. 
y artilugios del lenguaje que hacen de las cosas objetos polisémicos.

Pero hoy, las diversas economías tienden a ser captadas por un régimen donde todo debe ser rentable; incluso aquellos encuentros que apuntan a la construcción de sentidos están atravesados por la pregunta “¿quién gana más?”. Se pretende abolir toda forma de gratuidad; "el regalo" ha dejado de ser la entrega generosa que construye vínculos, para ser solo otra muestra de intercambio mercantil. Actualmente el totalitarismo globalizante del mercado neoliberal intenta absorber todas las formas de intercambio, atravesando las paredes de los espacios de mayor poder instituyente, o los más íntimos: los derechos civiles y de bienestar, la sexualidad, la subjetividad, etc. Régimen en el cual el sujeto mismo ha sido reducido a la condición de objeto y todas sus dimensiones se han convertido en mercancía. En este sentido, cada vez más, en la cotidianidad se constatan la fugacidad de los encuentros, la fragilidad de los lazos y, sobre todo, la necesidad de certezas que garanticen que con cada nuevo vínculo se obtendrá una ganancia concreta e inmediata.

La pretensión de convertirlo todo en objeto de consumo implica eliminar la referencia a cualquier valor trascendental, por ejemplo, la moral o la tradición ya no son necesarias para que se active el encuentro económico, es decir, ya no se requiere de un elemento tercero ni de una potencia superior que funja como soporte o como garante de un pacto. Lo que está en juego es el simple valor monetario de lo intercambiado y todo elemento exterior puede venir a entorpecer su libre circulación. Es así que la propuesta del neoliberalismo implica el empobrecimiento del universo simbólico, conlleva una cierta "desimbolización" del mundo que trae aparejada la reducción del sujeto a un objeto, es decir, implica para el sujeto, la pérdida del poder trasformador de su palabra.

Pero paradójicamente en medio de este contexto se ha dado el surgimiento de movimientos ciudadanos que plantean fuertes críticas a la imposición totalitaria del neoliberalismo y a su propuesta de reducir a los otros y a la naturaleza a la precaria condición de mercancías. Se trata de Los Indignados, que es la forma que ha tomado en España y otros países europeos, un movimiento social que surge de la indignación contra los regímenes autoritarios en el norte de África y rápidamente se expande por el viejo continente y Estados Unidos, es decir, que sigue una ruta inversa a la que han trazado las lógicas de dominación. Su actuar puede entenderse como el comienzo de una nueva propuesta de hacer la vida y la política, que aún no podemos predecir a dónde nos conducirá, pero que logra retomar la concepción clásica del hacer político como aquel que se orienta por la construcción de unas condiciones de vida según los intereses de los ciudadanos.

Estos movimientos podrían definirse como el arte de la resistencia pacífica que se propone hacer posible lo que parecía imposible, porque no solo han tenido la virtud de devolver la esperanza a quienes habían luchado en otras épocas sino que han logrado crear un espacio convocante para que las sociedades vuelvan a poner en el centro de su cotidianidad y de la vida pública, la pregunta por las formas de encuentro que están construyendo. Los Indignados, con su acto, extienden una invitación al conjunto de la sociedad para que ejerzan su poder político, pretenden rescatar la política de la gestión de los economistas y de los burócratas, son una voz nueva en un mundo donde las lógicas financieras de la economía neoliberal se han apoderado de la política.

Lo trascendente de estos movimientos, y por lo cual se diferencian de los que surgieron en otras épocas, es que en ellos participan grupos y sectores de la sociedad plurales y diversos, que no se unen a partir de identidades esenciales, sino justamente como crisol de diferencias. Se critica radicalmente al modelo económico, pero también evidencian el agotamiento del modelo de democracia formal representativa. "No nos representan" es la consigna común del movimiento, que aunque no propone otro 
"modelo" alternativo, (se aparta de cualquier forma de modelación) sí reivindica, en la más pura tradición de las revueltas parisinas del 68 , el derecho a la utopía: "Si no nos dejan soñar, no los dejaremos dormir", es la advertencia. De entrada no buscan derrocar los gobiernos ni introducir transformaciones estructurales al aparataje del Estado; se trata de otra forma de poder ciudadano que no se propone la toma del poder central y que, en cambio, moviliza fuerzas activas que se auto-convocan y auto-organizan para separase de las políticas prevalecientes que asfixian la vida. Allí confluyen luchas puntuales relacionadas con las realidades que se viven en cada una de las ciudades y territorios pero, sobretodo, se crean campos políticos para que emerja la fuerza de la diferencia; por eso el arco iris de sectores sociales que se han sumado: los expropiados de la vivienda, los jóvenes desempleados, los pensionados colocados en condición de extrema precariedad, las mujeres, los inmigrantes, los profesores, las expresiones de las distintas opciones sexuales. Se habla de renovar la democracia: de hecho se opta por métodos asambleístas de democracia directa y se interroga, en muchas áreas, de manera profunda al capitalismo. Es, en toda la extensión y hondura de la palabra, la constitución de un campo de afirmación de la vida, de búsqueda de caminos inéditos de reorganización de estas sociedades en crisis y que demuestra un enorme aprendizaje colectivo de formas de resistencia social noviolenta.

Si el movimiento ha conseguido el impacto mediático y la sensibilización de millones es además porque no se organiza en torno a la institucionalización de sus propuestas. Los partidos políticos tradicionales -sean ellos afiliados a los gobiernos o situados en la oposición- no han tenido ningún juego. La autonomía es un principio celosamente guardado entre Los Indignados. El veterano defensor de los Derechos Humanos S. Hessel, logró en pocas páginas resumir el sentir de la indignación generalizada y lo tradujo en su llamado a los jóvenes: “indignaos!”, tituló su folleto, de donde tomó su nombre el movimien- to. Allí señalaba todos los motivos que había para rebelarse, para superar la pasividad, tantos como en la época de los nazis que a él le tocó combatir. De ahí en adelante todo ha sido creatividad, innovación, coraje; y la movilización no ha cesado, se ha extendido por los barrios, se ha multiplicado en las asambleas más diversas, en las acciones directas noviolentas para impedir la expulsión de sus viviendas de los desahuciados por los bancos; para intentar detener el ajuste estructural que se quiere imponer a costa del salario y las condiciones de bienestar de la gente, para contribuir a develar los "no lugares" vacíos y los sinsentidos del sistema, para dar testimonio de la autodestrucción del sistema neoliberal, sin conceder terreno a la violencia.

La riqueza que expresan estos movimientos de resistencia plantea varios espacios de análisis a la investigación académica en las áreas de paz y de los movimientos sociales, pero en realidad nos llama a una discusión integral sobre las alternativas de reconstrucción de sociedad, de examen de estos nuevos poderes constituyentes que proclaman la necesidad de una democracia profunda. Sintámonos con responsabilidad para contribuir a generar herramientas conceptuales que estén a la altura de lo que está ocurriendo. Como siempre las páginas de polisemia están abiertas para este debate.

\section{En Polisemia 12}

La edición número 12 de POLISEMIA contiene cuatro artículos producto de investigación y tres de reflexión que contribuyen a la discusión sobre problemas sociales y humanos actuales para nuestra región.

La sección de artículos de investigación se abre con el texto Relaciones mutuas entre el individuo y la sociedad. Hacia una sociología de la individualidad de Carlos G. Juliao Vargas en el cual se trabaja en torno al objeto de estudio de las ciencias sociales a partir de tres rutas: en primer lugar desde el punto de vista histórico, antropológico y sociológico; luego desde un punto de vista 
epistemológico y metodológico y finalmente introduciendo una reflexión sobre las identidades en el mundo globalizado. El segundo artículo de esta sección es Madres de la Plaza de Mayo (19761984): múltiples espacios en la formación de la opinión pública de Darío Ocampo y Diana Arango donde los autores, a partir del estudio de las acciones realizadas por la Fundación Madres de la Plaza de Mayo, evidencian la importancia de la mediación de las víctimas en la configuración de la opinión pública sobre los hechos de violencia que los afectaron.

El tercer artículo es El desarrollo de la categorización: Perspectivas tradicionales y contemporáneas de María Clara Garavito. Allí la autora, reconociendo la relevancia que tiene el proceso de categorización en la configuración de la realidad de los seres humanos, realiza un recorrido que va desde las reflexiones tradicionales sobre forma-función hasta las nuevas perspectivas de la cognición corporizada, para evidenciar los aportes que ofrecen estas visiones y las preguntas que quedan abiertas para nuevas investigaciones sobre los procesos de categorización. El cuarto artículo de esta sección es Medición de la pobreza en contextos de crisis. Una visión desde la perspectiva de la ciudadania social de Oscar Useche. En este artículo el autor, en el contexto del debate sobre la ciudadanía de derechos sociales, realiza un análisis de las formas de medición de la pobreza evidenciando la evolución que se ha dado en los enfoques e indicando los alcances y limitaciones de los distintos índices de medición que se usan actualmente.

En la sección de artículos de reflexión se presentan tres trabajos. El primero Arte y violencia: la representación del daño como forma de reconstrucción de una nueva sociedad es escrito por Giovanny Moisés
Pinzón Perilla, quien, partiendo de una compresión del arte como hecho en la vida del hombre, da cuenta de la relación entre el arte y la violencia y de la importancia de éste en la creación de una cultura noviolenta que ofrece alternativas para la restitución del derecho a la justicia de las víctimas. El segundo artículo es El concepto de 'perversidad' en Edgar Allan Poe. Una reflexión filosófica, escrito por Juan F. Manrique. En este texto el autor retoma las reflexiones que Edgar Alan Poe hace sobre la perversidad en sus cuentos The black cat $\mathrm{y}$ The imp of the perverse $\mathrm{y}$ las pone en diálogo con algunas doctrinas filosóficas y teológicas que han abordado esta temática. En el artículo se destaca la originalidad y los aportes que hace la literatura de Poe a la filosofía y a la teología para enriquecer el debate. Finalmente, en esta sección se presenta el artículo La actividad filosófica según Wittgenstein. Confusiones conceptuales e investigación gramatical escrito por Oscar Espinel. Allí, el autor retoma la diferencia que hace Wittgenstein entre explicación y distinción como formas de abordar objetos de estudio disímiles y manifiesta que esta diferenciación está a la base de su propuesta de investigación gramatical como acción propiamente filosófica.

Para cerrar este número de nuestra revista, Luís Gerardo Díaz en la sección de reseñas, presenta el libro Religión sin redención escrito por Luís Martínez Andrade, que se constituye en un nuevo aporte al debate de las ciencias sociales en el contexto latinoamericano.

Esperamos que los lectores de POLISEMIA encuentren en los artículos de este número elementos que les permitan nutrir sus investigaciones y búsquedas académicas con nuevas reflexiones y preguntas. 